\title{
Effects of Repeated Baking on the Mechanical and Physical Properties of Metal-Ceramic Systems
}

\author{
Sakae NAGASAWA ${ }^{1,2}$, Takamitsu YOSHIDA ${ }^{1,3}$, Toshihide MIZOGUCHI ${ }^{4}$, Nobuyoshi TERASHIMA ${ }^{1}$, \\ Kuni KAMIJYO ${ }^{5}$, Michio ITO $^{1,2}$ and Yoshiki OSHIDA ${ }^{6}$ \\ ${ }^{1}$ Department of Dental Materials \\ ${ }^{2}$ Division of Biomaterials, Institute for Oral Science \\ ${ }^{3}$ Division of Implantlogy, Institute for Oral Science \\ ${ }^{4}$ Institute for Oral Science \\ ${ }^{5}$ Department of Orthodontics Matsumoto Dental University, 1780 Gobara, Hirooka Shiojiri, Nagano Japan \# 399-0781 \\ ${ }^{6}$ Dental Materials Division, Department of Restorative Dentistry, Indiana University School of Dentistry, 1121 West Michi- \\ gan Street, Indianapolis, IN 46202, USA \\ Corresponding author, E-mail:snagasawa@po.mdu.ac.jp
}

Received January 13, 2004/Accepted March 19, 2004

This study evaluates effects of repeated baking processes on the mechanical and physical properties of single and triple applications of opaque, body and enamel porcelains fused to three different metal substrates (precious metal, semi-precious metal and non-precious metal). The vintage halo porcelain system was employed and fused to metals. Fused samples were subjected to three-point bend tests to evaluate bend strength and modulus of elasticity.

It was found that, by increasing repeated baking cycles, (1) body and enamel porcelains increased bend strengths but opaque porcelain did not show any changes, (2) all triple-layered porcelains fired to metals increased bend strengths, and (3) all three porcelains and metal substrates did not exhibit changes in thermal expansion percentage.

It was concluded that repeating baking procedures up to 10 cycles did not exhibit any adverse effects on the final properties of porcelain-fired to metals, rather it was noticed that mechanical strengths increased by increasing cycles.

Key words: Porcelain bond strength, Metal-porcelain interface, Internal stress generation

\section{INTRODUCTION}

In connection with a rise of the aesthetic demand to dental treatment, porcelain and composite resin were popularly used and many researches have been made $^{1-6)}$. Furthermore, dental porcelain is the excellent material in the biocompatibility.

In order to perform the final fine adjustments of prepared restorations to patient tooth color and morphology, a plurality of baking cycles is normally conducted during the firing of porcelain to metallic copings. However, it has been reported that repeated baking caused some adverse effects on the final prostheses. For example, by increasing the number of repeated bakings, "the internal strain will be developed and accumulated enough to cause a reduction in mechanical properties" ${ }^{7)}$, "the transparency and surface smoothness of fired porcelain will be deteriorated"8), or "the too frequent refiring will result in lifeless and overly translucent porcelain" $"$. These adverse effects were discussed about 20 to 30 years ago $^{10-15)}$, and little is known about currently available porcelain materials in terms of the influence of baking cycles on mechanical and physical properties. Therefore, it is necessary to investigate the influence of repeated baking cycles on the mechanical and physical properties of current porcelain materials.

In our previous work ${ }^{16)}$, the opaque, body, and enamel of the Vintage halo porcelain system (Shofu) were fired to precious metal $(72 \mathrm{Au}-13 \mathrm{Pt}-9.7 \mathrm{Pd}-2.8 \mathrm{Ag}$ by weight \%) in either a single-layer or triple-layer application. It was found that ( $i$ ) the three-point bend strengths increased by increasing baking cycles up to 10 cycles, (ii) the average surface roughness decreased by increasing the number of baking procedures, (iii) changes in color characteristics were very small in the Vintage halo porcelain system, and (iv) since the pores entrapped in the porcelain remained even by increasing baking cycles, it was recommended to remove the surface pores prior to forming the next layer when handling the highly viscous opaque porcelain.

In the present study, two other types of alloys (i.e., semi-precious $\mathrm{Au}-\mathrm{Pd}-\mathrm{Ag}$ alloy and non-precious $\mathrm{Co}-\mathrm{Cr}$ alloy) were added to evaluate and compare mechanical and physical properties among three different types of alloys fired to the porcelain. Moreover, the interfacial stress development was analyzed by the finite element method and the neutral axis calculation.

\section{MATERIALS AND METHODS}

\section{Materials}

As for porcelain materials, the opaque (A1O), body (A1B), and enamel (OP57) of the Vintage halo 
Table 1 Degassing and baking conditions for metals and porcelains

\begin{tabular}{llccc}
\hline \multicolumn{1}{c}{ Material } & \multicolumn{1}{c}{$\begin{array}{c}\text { Condensing time, } \\
\text { drying conditions, etc. }\end{array}$} & $\begin{array}{c}\text { Baking } \\
\text { temp. }\left({ }^{\circ} \mathrm{C}\right)\end{array}$ & $\begin{array}{c}\text { Heating } \\
\text { rate } \\
\left({ }^{\circ} \mathrm{C} / \mathrm{min}\right)\end{array}$ & $\begin{array}{c}\text { Baking } \\
\text { numbers }\end{array}$ \\
\hline A1O single-layer & 5 min + air dry & $650 \rightarrow 940$ & 55 & $1,3,5,7,10$ \\
\hline A1B single-layer & 5 min + tissue paper & $650 \rightarrow 920$ & 55 & $1,3,5,7,10$ \\
\hline OP57 single-layer & 5 min + tissue paper & $650 \rightarrow 920$ & 55 & $1,3,5,7,10$ \\
\hline KIK & $\begin{array}{l}\text { Stress-relief at } 1000^{\circ} \mathrm{C}, 10 \text { min } \\
\text { Sand blasting } \\
\text { Degassing at } 1050^{\circ} \mathrm{C}, 15 \text { min }\end{array}$ & $650 \rightarrow 920$ & 55 & $0,1,3,5,7,10$ \\
\hline J2 & $\begin{array}{l}\text { Sand blasting } \\
\text { Degassing at } 980^{\circ} \mathrm{C}, 10 \text { min }\end{array}$ & $650 \rightarrow 920$ & 55 & $0,1,3,5,7,10$ \\
\hline $\begin{array}{l}\text { DnTi } \\
\text { Sand blasting }\end{array}$ & $\begin{array}{l}\text { Degassing at } 900^{\circ} \mathrm{C}, 1 \text { min } \\
\text { Sand blasting }\end{array}$ & $650 \rightarrow 920$ & 55 & $0,1,3,5,7,10$ \\
\hline $\begin{array}{l}\text { Triple-layer firing on } \\
\text { metals (KIK, J2, DnTi) } \\
\text { plates }\end{array}$ & $\begin{array}{l}\text { Two applications of opaque, } \\
\text { followed by same conditions for } \\
\text { single-layer application and } \\
\text { finally glazed }\end{array}$ & $\begin{array}{l}650 \rightarrow 940 \\
650 \rightarrow 920\end{array}$ & 55 & $1,3,5,7,10$ \\
\hline
\end{tabular}

Note: The water mixing ratio for $\mathrm{A} 1 \mathrm{O}$ was 0.25 and 0.36 for $\mathrm{A} 1 \mathrm{~B}$ and $\mathrm{OP} 57$, respectively.

porcelain system (Product No.PN7521, Shofu Inc., Kyoto Japan) were chosen. For metallic coping materials, three alloys were selected. They included (1) the precious metal system KIK-HII (Product No.1111404, Ishifuku Metal Ind. Co. LTD., Tokyo Japan) - $72 \% \mathrm{Au}, 13 \% \mathrm{Pt}, 9.7 \% \mathrm{Pd}, 2.8 \% \mathrm{Ag}$, (2) the semi-precious metal system Degubond-J2 (Product No.015564, Degussa-Huls AG, Hanau Germany)$40 \% \mathrm{Au}, 35.6 \% \mathrm{Pd}, 17.6 \% \mathrm{Ag}, 5.0 \% \mathrm{Sn}, 1.0 \% \mathrm{Pt}, 0.2 \% \mathrm{Ir}$, and (3) the non-precious metal system DENTITAN (Product No.9586, Krupp Medizintechnik GmbH, Harkortstrasse Germany) $-69.5 \% \mathrm{Co}, 24.0 \% \mathrm{Cr}, 2.0 \% \mathrm{Mo}$, $2.0 \% \mathrm{Ti}$. Hereinafter, the following marks will be used in this manuscript: $\mathrm{A} 1 \mathrm{O}$ for opaque porcelain A1O, A1B for body porcelain A1B, OP57 for enamel porcelain OP57, KIK for precious metal KIK-HII, J2 for semi-precious palladium system alloy DegubondJ2, and DnTi for non-precious DENTITAN alloy.

\section{Casting of metal coping plates}

An acrylic sheet for the purpose of casting (CLAREX, Nitto Jushi Kogyo Co. Ltd. Tokyo, Japan, $0.5 \mathrm{~mm}$ thickness) was cut into rectangular shapes $(25 \mathrm{~mm}$ long $\times 10 \mathrm{~mm}$ wide) and invested with phosphate-bonded investment. The mold was preheated at $800^{\circ} \mathrm{C}$ and each metal was cast using a hifrequency centrifugal casting machine (THERMOTROL II, Model 340102, Sekisui Denshi Co. Ltd., Shiga, Japan).

\section{Porcelain firing schedule and re-firing condition}

For single firing porcelain application, an individual porcelain material was kneaded with distilled water, and was then filled into the rectangle mold $(25 \mathrm{~mm}$ $\times 10 \mathrm{~mm} \times 2 \mathrm{~mm}$ ), followed by 5 -minute condensing with a supersonic condenser (Ceramosonic Condenser Cera Con II, Model SCC- II , No.0191703, Shofu Inc., Kyoto, Japan).

A triple-layered sample with three-layer application (comprised of opaque, body, and enamel porcelain; each layer's thickness was about $0.5 \mathrm{~mm}$ ) was prepared on metallic copings under the same conditions, as shown in Table 1.

For each single-layered porcelain, the re-firing condition at repeated baking was the same as the first firing condition. The triple-layered and metal samples were re-fired in a firing condition of enamelporcelain (OP57). For each sample condition (total 48 groups), 10 samples were prepared $(n=10)$.

\section{Mechanical property evaluation}

Mechanical property evaluation was preformed by three-point bending flexure tests at a crosshead speed of $0.5 \mathrm{~mm} / \mathrm{min}$. Using a universal test machine (Autograph AG-500D, Shimadu, Kyoto, Japan), the distance between the supporting bars was $20 \mathrm{~mm}$, and the porcelain side of a triple-layered specimen was placed under tension. The maximum bend strengths and modulus of elasticity (MOE) were obtained. Mean values and standard deviations for each group $(n=10)$ were calculated. Two-way analysis of variance followed by the Student-NewmanKeuls test for multiple comparison was used to identify significant differences between porcelain types at the $95 \%$ confidence level.

\section{Thermal expansion measurement}

Using mechanically tested samples, the thermal expansion of metals and porcelains were measured with a thermomechanical analyzer (TMA-50, Shimadu, 
Kyoto, Japan). Mean values and standard deviations for each group $(n=3)$ were calculated.

\section{Numerical analysis}

Based on the obtained results on mechanical (MOE values) and thermal (coefficient of thermal expansion) properties, deformation and stress distribution were estimated by the finite-element-method (FEM), which was developed by the $\mathrm{C}++$ language analysis program (programmed by Nagasawa, S.). Rectangular and constant strain elements were used. Stress analysis was done only on the right side half and a complete frame was compiled via the photo-shop technique for a final display. For analysis, the supporting distance was $20 \mathrm{~mm}, 2 \mathrm{~mm}$ thick, $10 \mathrm{~mm}$ wide, and $12.5 \mathrm{~mm}$ long (which was half of the $25 \mathrm{~mm}$ total length). This half of the sample was divided into 860 elements with 924 nodes. The program was also used for the thermal stress analysis. For calculations, the Poisson's ratios of 0.2 for porcelain and 0.39 for DnTi were used.

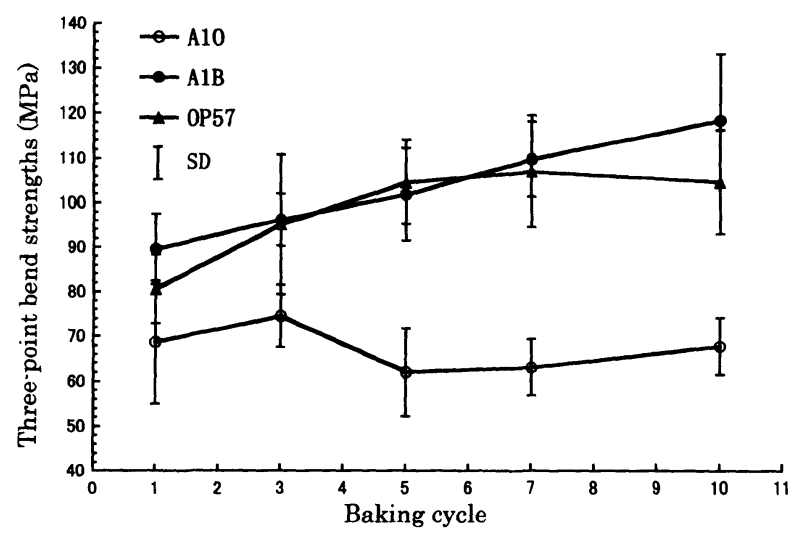

Fig. 1 Changes in bend strengths of three different porcelains as a function of repeated baking numbers.

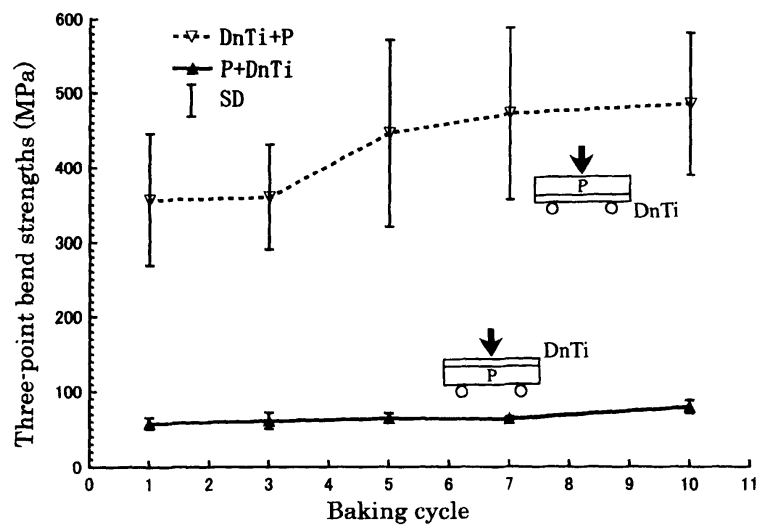

Fig. 3 Comparison of porcelain placed side on bend strengths of triple application on Dentitan as a function of repeated baking numbers.

\section{RESULTS}

Mechanical property evaluation

The effect of number of repeated bakings on bend strengths is shown in Fig. 1 for single-layered porcelains. Hereinafter, the data of single-layered porcelains and triple-layered porcelain on KIK from our previous work were used ${ }^{16)}$. Fig. 2 shows similar results for triple-layered porcelain $\mathrm{P}$ (comprising of opaque, body, and enamel) on three different metals, $\mathrm{KIK}$, DnTi, and J2, when the porcelain side (P) was placed on the maximum tension side while conducting the three-point bending tests. If the metal side is placed on the maximum tension side, the results should be different. Fig. 3 compares these two cases for porcelain-DnTi combination.

The bend strengths of A1B, OP57 and triplelayer porcelain on metals showed an increasing tendency by increasing the repeated baking cycles $(\mathrm{P}<0.05)$. On the other hand, A1O did not show any changes (see Fig. 1) $(\mathrm{P}<0.05)$. Furthermore, it was found that when the metal side was placed on

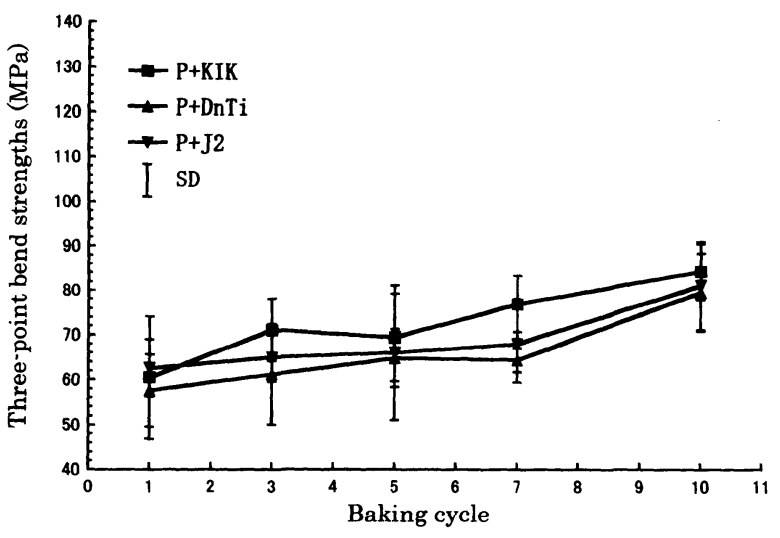

Fig. 2 Changes in bend strengths of triple application on three different metals as a function of repeated baking numbers.

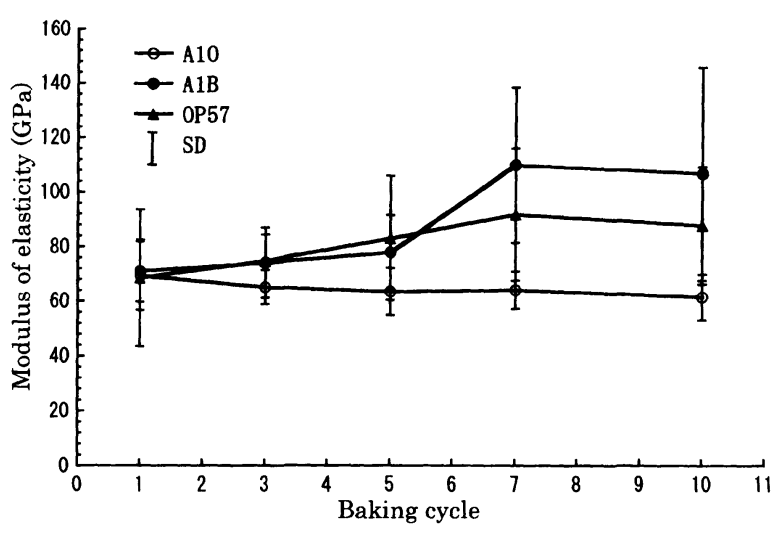

Fig. 4 Changes in modulus of elasticity of three different porcelains as a function of repeated baking numbers. 
the tensile stress side, bend strengths were about 6 times higher than in the case when the porcelain was placed on the maximum tensile stress side (see Fig. 3).

The effects of baking cycles on the modulus of elasticity (MOE) are shown in Fig. 4 for singlelayered porcelain, Fig. 5 for metals, and Fig. 6 for triple-layered porcelain on metals with different bending directions. In Fig. 5, data points at 0 (zero) baking cycle indicate values of the post-degassing

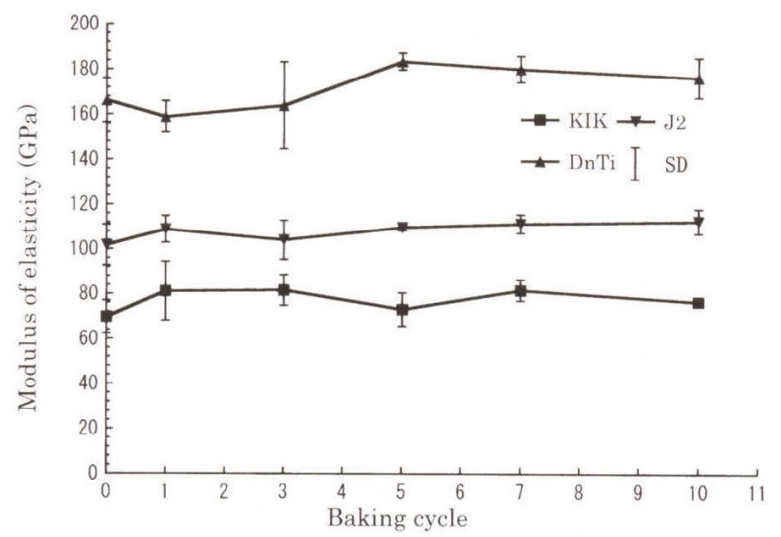

Fig. 5 Changes in modulus of elasticity of three different metals as a function of repeated baking numbers.

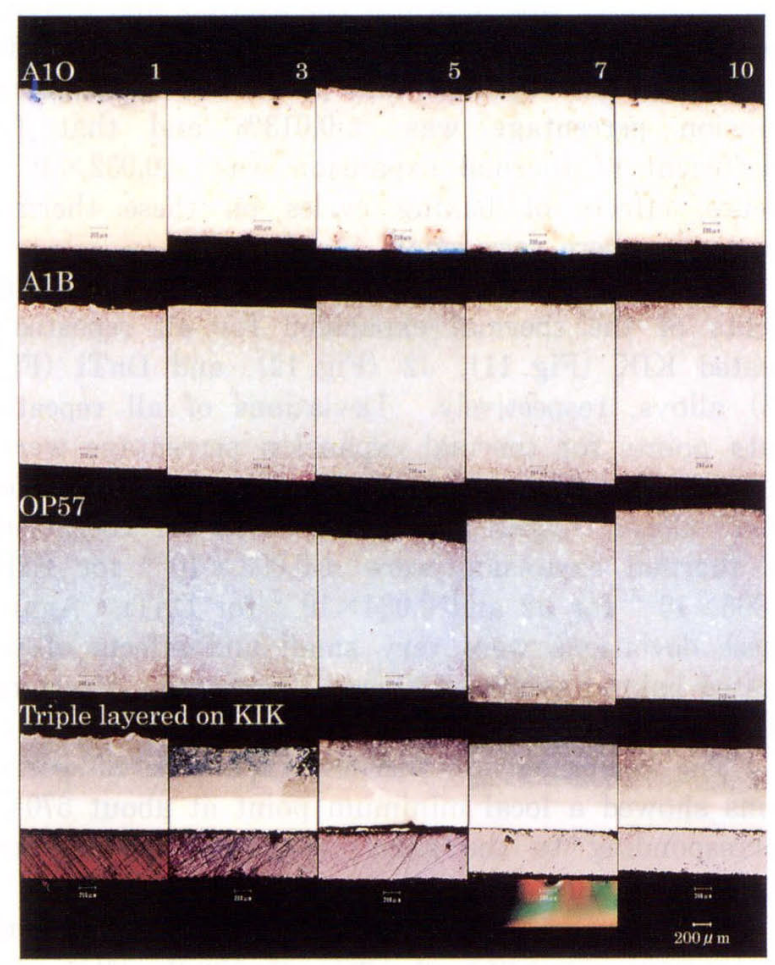

Fig. 7 Changes in photomicrographs of four different types of porcelains as a function of repeated baking numbers. treated samples.

The MOE of A1B and OP57 showed an increasing tendency by increasing the repeated baking cycles while A1O did not show any changes by increasing the repeated baking cycles. This was similar for three-point bend strength $(\mathrm{P}<0.05)$.

With the precious (KIK) and semi-precious (J2) metal systems, the MOE was increased slightly by the first baking and did not change thereafter. However, the MOE value of the non-precious metal

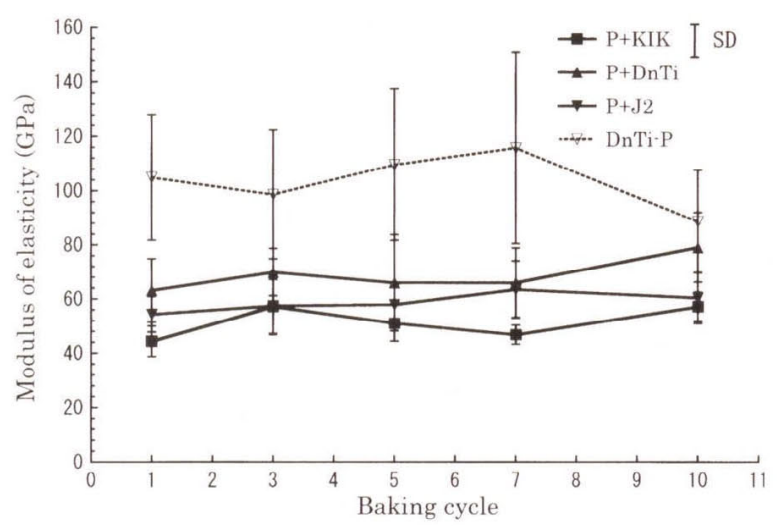

Fig. 6 Changes in modulus of elasticity of triple application on three different metals as function of repeated baking numbers.
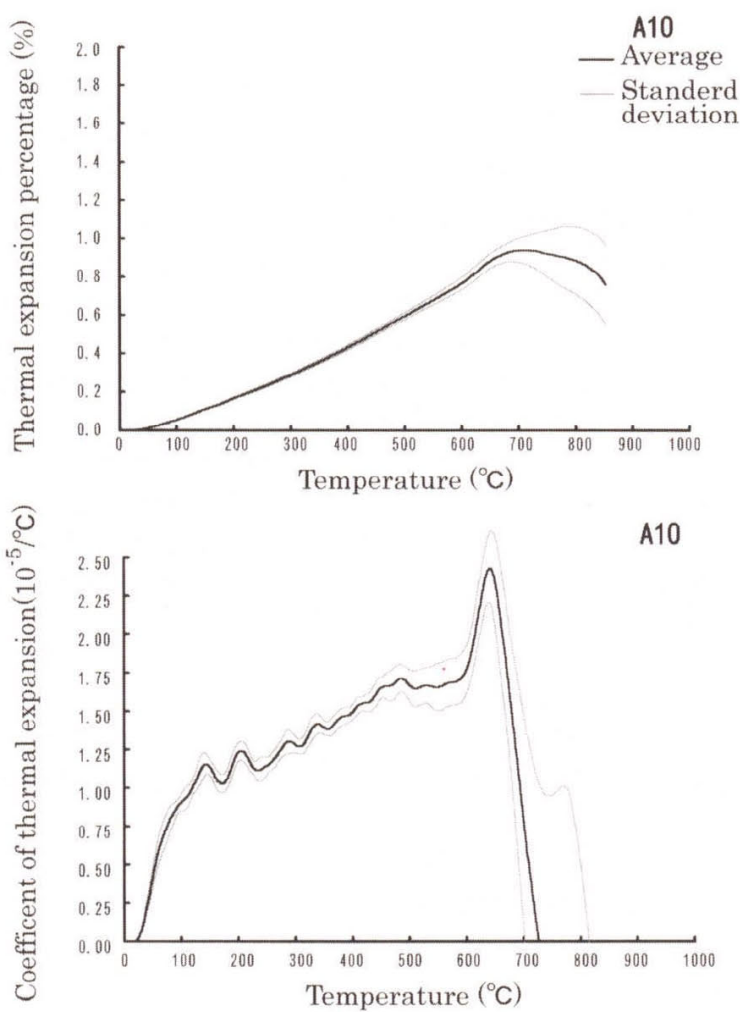

Fig. 8 The percentage and coefficient of thermal expansion of $\mathrm{A} 1 \mathrm{O}$ porcelains. 

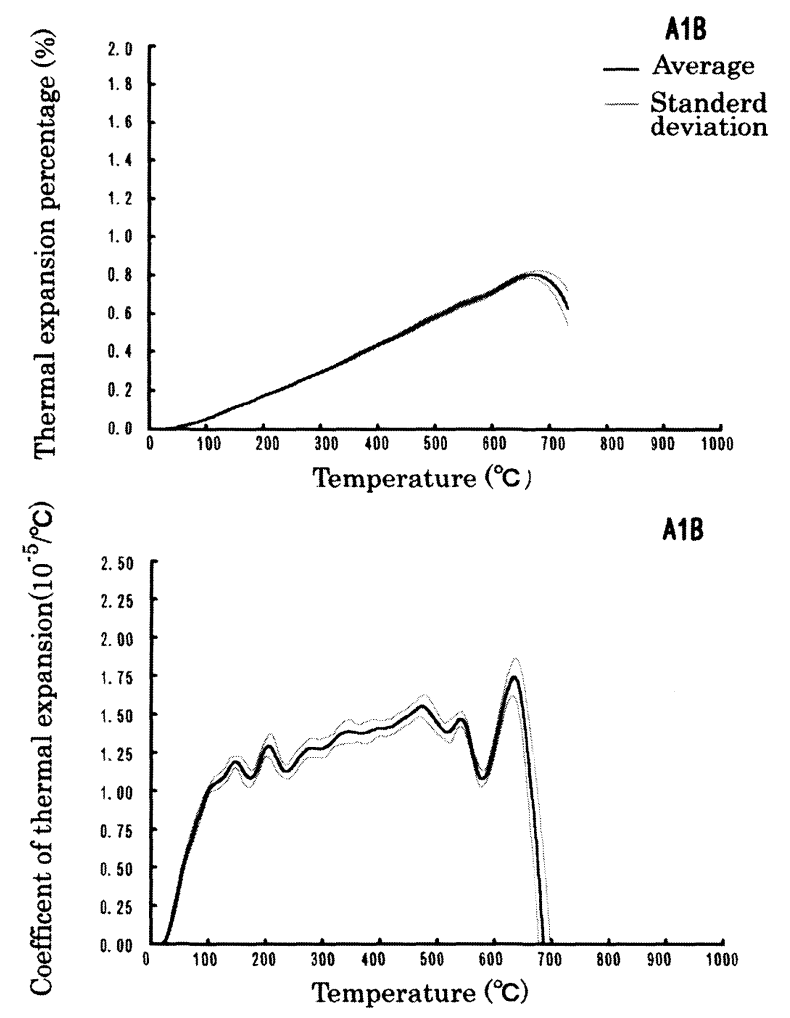

Fig. 9 The percentage and coefficient of thermal expansion of $\mathrm{A} 1 \mathrm{~B}$ porcelains.

(DnTi) was decreased by the first baking, increased by the $5^{\text {th }}$ baking cycle, and then decreased by the $10^{\text {th }}$ baking cycle $(\mathrm{P}<0.05)$. Moreover, the averaged value of the MOE was about $80 \mathrm{GPa}$ for KIK, 110 $\mathrm{GPa}$ for J2, and $180 \mathrm{GPa}$ for DnTi, respectively.

When the porcelain was placed on the tensile stress side while conducting the three-bending tests, the MOE of the triple-layer porcelain fired on metals did not show changes by increasing the repeated baking cycles, but was influenced by the types of metal system $(\mathrm{P}<0.05)$. Furthermore, when the metal side was placed on the tensile stress side $(\mathrm{DnTi}+\mathrm{P})$, the MOE was about 1.5 to 2 times higher than when the porcelain was placed on the tensile stress side $(\mathrm{P}+\mathrm{DnTi}) \quad($ see Fig. 6) $\quad(\mathrm{P}<0.05)$.

\section{Changes in Appearance}

Fig. 7 shows the sequential changes in a photomicrograph of each $\mathrm{A} 1 \mathrm{O}, \mathrm{A} 1 \mathrm{~B}, \mathrm{OP} 57$, and triple- layered porcelain fired on the KIK metal system.

A plurality of color particles and pores were observed, but their shapes and numbers appeared not to change by increasing the baking cycles.

\section{Thermal expansion measurement}

Figs. 8, 9, and 10 show percentages and coefficients of the thermal expansion for all repeatedly baked A1O (Fig. 8), A1B (Fig. 9), and OP57 (Fig. 10) porcelains.
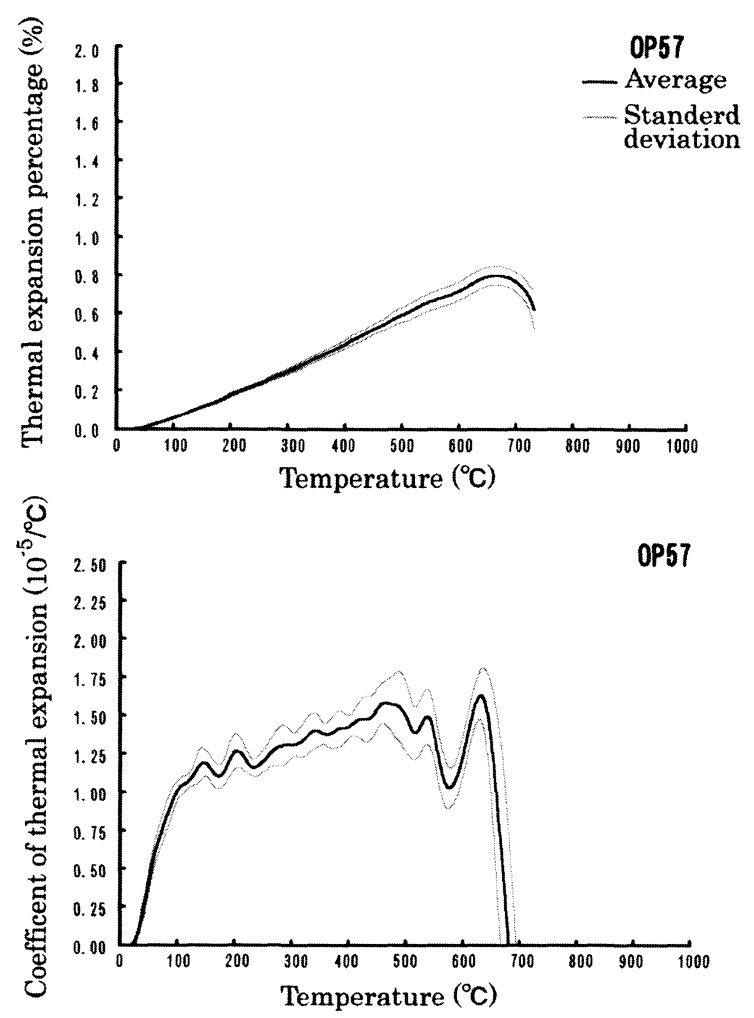

Fig. 10 The percentage and coefficient of thermal expansion of OP57 porcelains.

The bold-faced line indicates the average and grayish lines indicate the standard deviation range. The deviation for all repeated data points for thermal expansion percentage was $\pm 0.013 \%$ and that for coefficient of thermal expansion was $\pm 0.032 \times 10^{-5}$. Hence, effects of baking cycles on these thermal properties were very small.

Figs. 11, 12, and 13 show percentages and coefficients of the thermal expansion for all repeatedly heated KIK (Fig. 11), J2 (Fig. 12), and DnTi (Fig. 13) alloys, respectively. Deviations of all repeated data points for thermal expansion percentage were $\pm 0.026 \%$ for $\mathrm{KIK}, \pm 0.025 \%$ for $\mathrm{J} 2$ and $\pm 0.015 \%$ for DnTi alloys, respectively. Deviations for coefficient of thermal expansion were $\pm 0.093 \times 10^{-5}$ for KIK, $0.066 \times 10^{-5}$ for $\mathrm{J} 2$ and $0.084 \times 10^{-5}$ for DnTi. Again, these deviations were very small and effects of repeated baking cycles on thermal properties of coping alloys were minimal.

The coefficient of thermal expansion of porcelains showed a local minimum point at about $570^{\circ} \mathrm{C}$, corresponding to the glass transition temperature, $\mathrm{T}_{\mathrm{g}}$, of porcelains.

Furthermore, the rapid increase in the coefficient of thermal expansion of DnTi at about $700^{\circ} \mathrm{C}$ (see Fig. 13) should be related to phase transformation from $\alpha$ Co to $\beta$ Co. The $\alpha$ Co solid solution phase has an HCP structure with $\mathrm{a}_{\mathrm{o}}$ of $2.51 \AA$ and $\mathrm{c}_{\mathrm{o}}$ of 4.07 

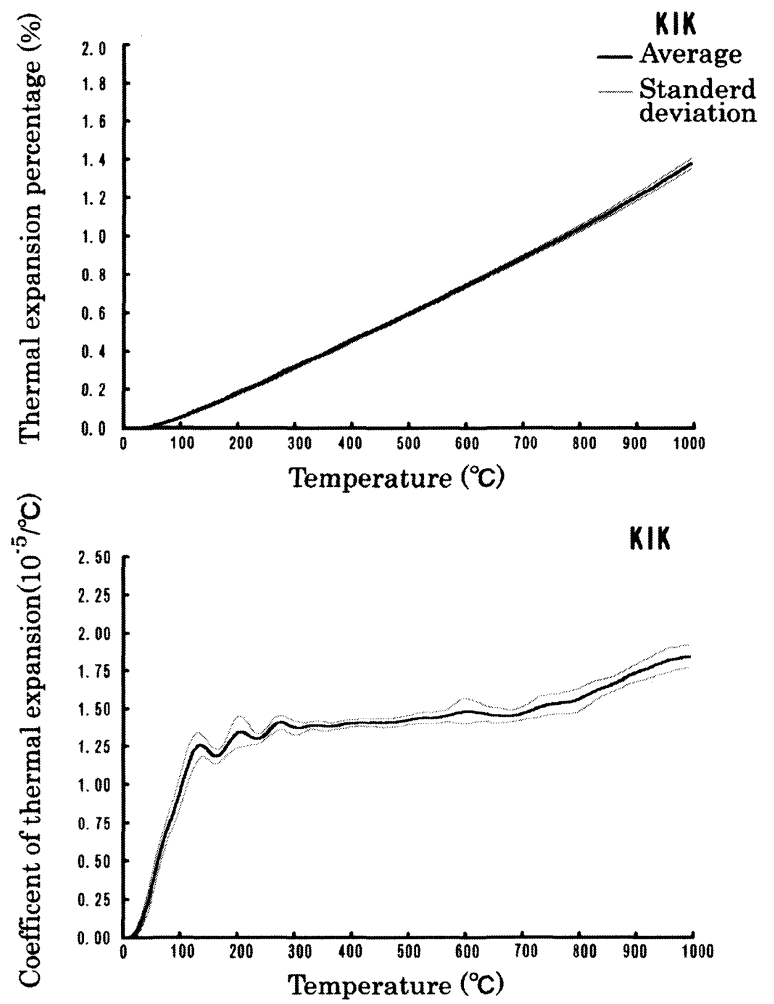

Fig. 11 The percentage and coefficient of thermal expansion of KIK metals.
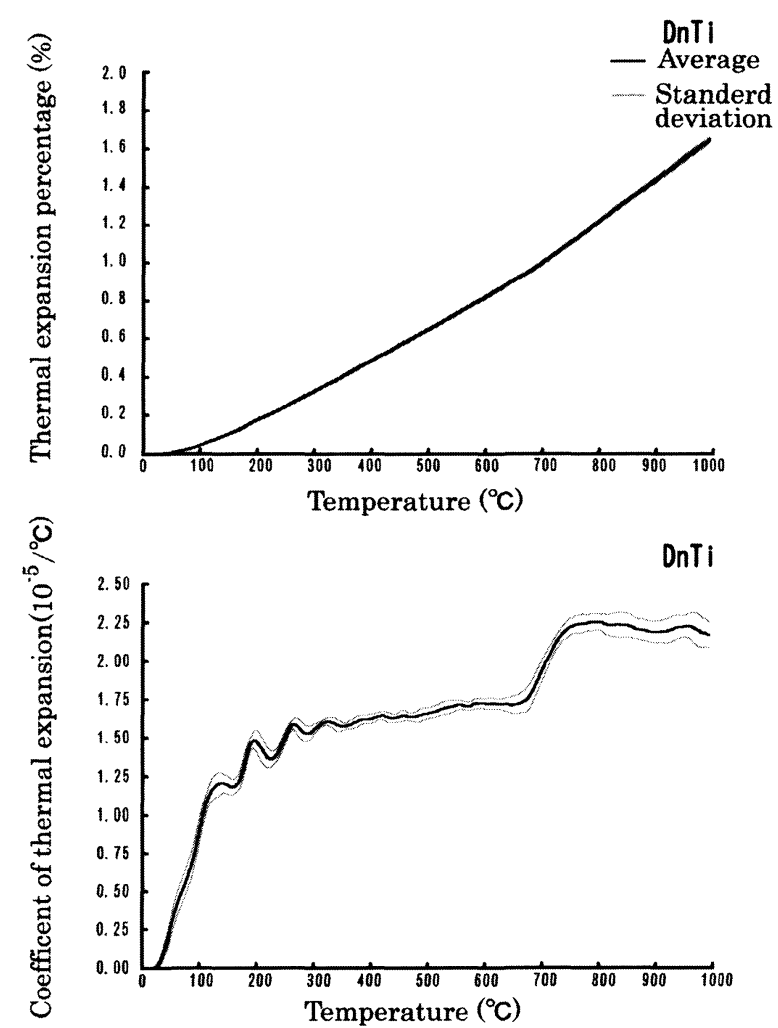

Fig. 13 The percentage and coefficient of thermal expansion of Dentitan metals.
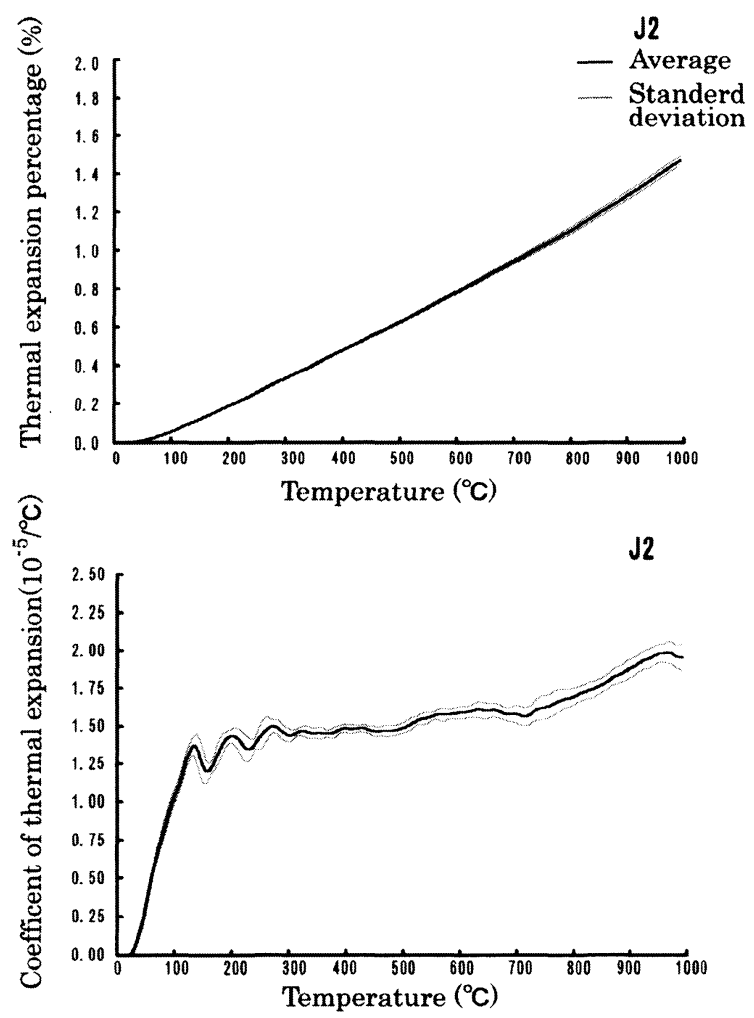

Fig. 12 The percentage and coefficient of thermal expansion of $\mathrm{J} 2$ metals.

$\dot{A}$, while the $\beta$ Co solid solution phase has an FCC structure with $\mathrm{a}_{0}$ of $3.54 \AA^{17,18)}$.

\section{Numerical analysis}

Fig. 14 shows the distortion and principal stress distribution patterns at the bending test of first baked porcelains obtained from the numerical analysis. The magnitude of the principal stress was shown with colors and the distortions were presented by a 100 fold magnification. The term $"-470^{\circ} \mathrm{C}$ " in $\mathrm{P}+\mathrm{DnTi}$ $-470{ }^{\circ} \mathrm{C}$ indicates the case when the sample was cooled from $500^{\circ} \mathrm{C}$ to room temperature (i.e., $30^{\circ} \mathrm{C}=$ $500-470)$. It was found that, when the DnTi was placed on the maximum tensile stress side (DnTit P), larger tensile stress was generated on the metal side. Moreover, when the cooling was taken into account $\left(\mathrm{P}+\mathrm{Dn} \mathrm{Ti}-470^{\circ} \mathrm{C}\right)$, the distortion was about twice that of the non-cooling model $(\mathrm{P}+\mathrm{DnTi})$.

Fig. 15 shows the stress distribution in depth at the mid-span of the test sample. In general, the upper side showed the maximum compressive stress and the bottom side showed the maximum tensile stress. Again, it was found that the stress distribution pattern when the metal (DnTi) side was placed on the tension side (marked with open diamonds) showed a different pattern from that when the porcelain side was on the maximum tension (marked with closed diamonds). 


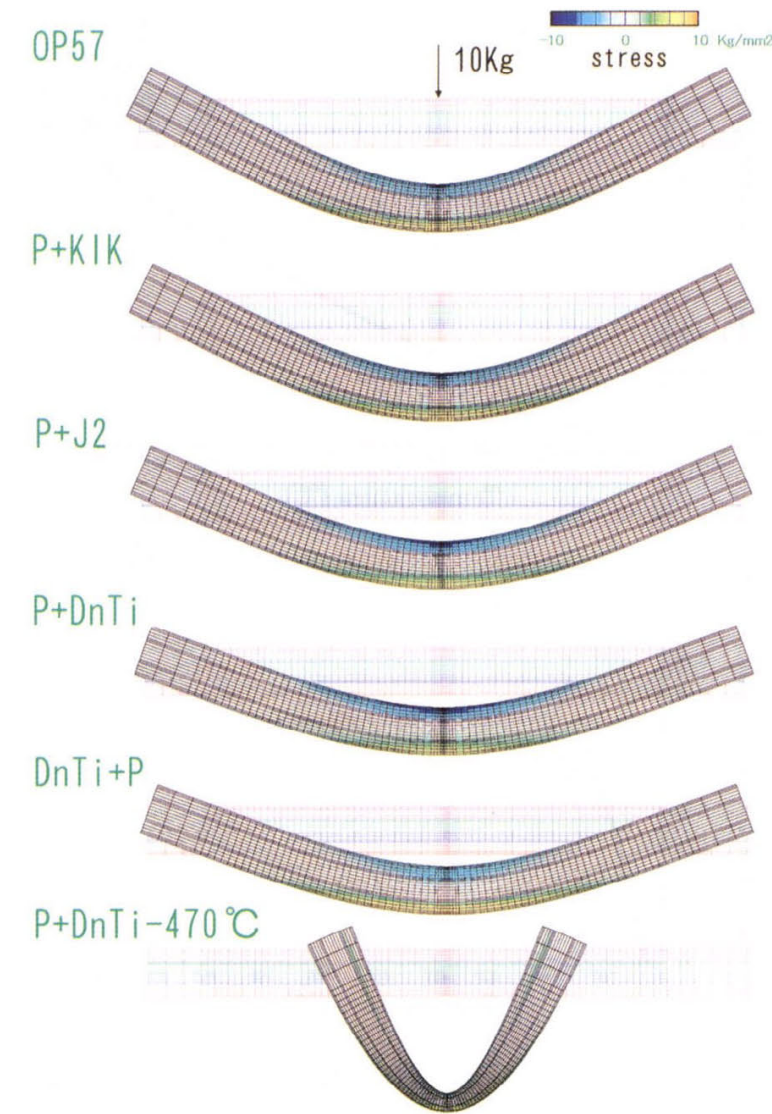

Fig. 14 Stress and distortion of first baked porcelains form the analysis of finite element method.

Fig. 16 shows the cooling effect on the maximum stress. The term "0Kg" in the legend indicates the no-load was applied. In the condition $(\mathrm{P}+\mathrm{DnTi}-470$ ${ }^{\circ} \mathrm{C}+0 \mathrm{Kg}$ ) when the sample was only subjected to cooling and no-loading, tensile stresses were observed on metal and enamel porcelain sides (OP57). These tensile stresses were caused by the mismatch in the coefficients of thermal expansion of the metal to opaque, body and enamel porcelains. In the case when the sample was subjected to both cooling and loading $\left(\mathrm{P}+\mathrm{DnTi}-470^{\circ} \mathrm{C}\right)$, the value of tensile stress at the surface was slightly larger than that of the single layer porcelain (OP57).

\section{DISCUSSION}

Repeated cycle effects

In 1971, Ohtake ${ }^{11}$ measured the Knoop hardness and strengths (compressive, bend, and tensile) of opaque porcelains, reporting that mechanical strengths reduced to one third of the maximum strengths (which were achieved at $1000^{\circ} \mathrm{C}$ ) when the porcelain firing temperature increased to $1050{ }^{\circ} \mathrm{C}$. For the enamel porcelain, similar studies conducted by $\mathrm{Kuroe}^{13)}$ indicated that when the firing temperature was $1030^{\circ} \mathrm{C}$, the compressive strengths decreased down to less

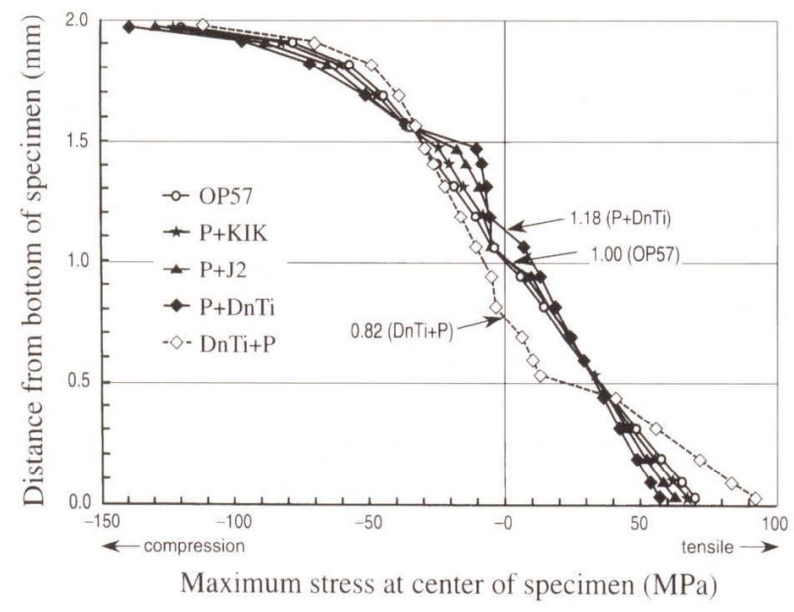

Fig. 15 The maximum stress at center of OP57 porcelain and triple application on three different metal plates.

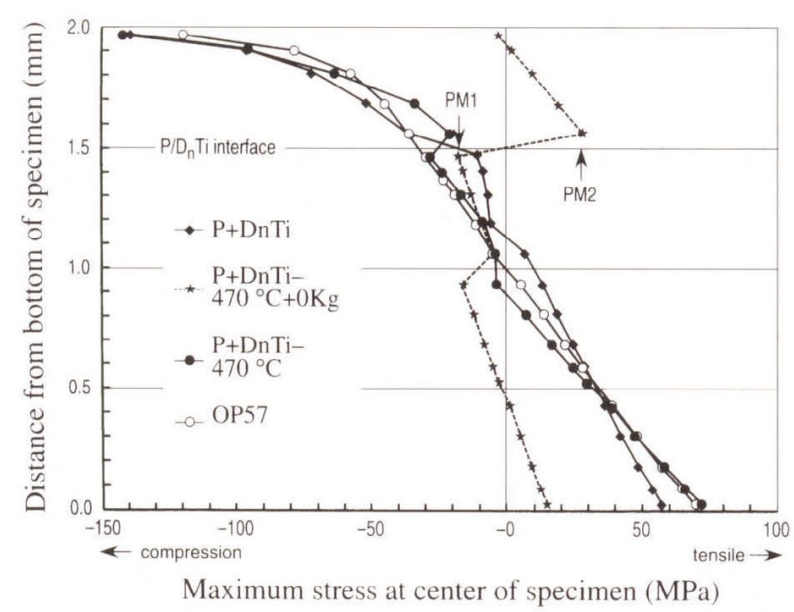

Fig. 16 The maximum stress at center of OP57 porcelain and triple application on three different metal plates.

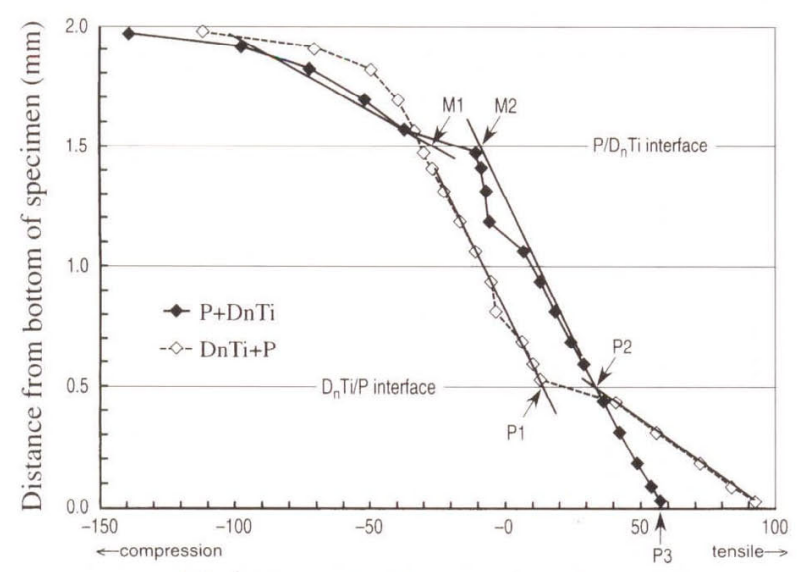

Maximum stress at center of specimen ( $\mathrm{MPa})$

Fig. 17 Interfacial stresses at metal and porcelain layers. 
than half of the strengths which were achieved at 980 ${ }^{\circ} \mathrm{C}$. Both studies reported that the Knoop hardness did not change even if the firing temperature increased.

On the other hand, Yamada et $a l^{14)}$ compared different types of porcelain (the high fusing type, medium fusing type, and low fusing type) and conducted compressive tests. It was reported that the porcelain strengths were improved when the firing temperature were increased up to $5 \%$ (in other words, about $45 \sim 65^{\circ} \mathrm{C}$ ) of the manufacturer's recommended firing temperatures. In 1980, Iwata $^{12)}$ conducted similar tests on opaque, body, and enamel porcelains, concluding that even if the porcelain was fired above $1000{ }^{\circ} \mathrm{C}$, the strengths increased very slightly or did not show remarkable changes.

The statement "by increasing numbers of repeated baking procedures during the porcelain firing to metal copings, the internal strain would be developed and accumulated enough to cause a reduction in mechanical properties" ${ }^{7)}$ was made based on results reported by Ohtake ${ }^{11)}$ and Kuroe ${ }^{13)}$. However these reports conflicted with the reports by Iwata ${ }^{12)}$ and Yamada et al. ${ }^{14)}$ As seen in Fig. 1, our results indicated that the bend strengths increased by increasing baking cycles. On the contrary, OP57 porcelain showed a slight reduction after 10 baking cycles compared to the sample fired after 7 cycles.

Also the statement "the internal strain would be developed and accumulated enough to cause a reduction in mechanical properties" was hypothesized from the change of thermal expansion by baking. However, as was shown in Figs. 11 through 13, the thermal expansions of alloys were not influenced by repeated baking. On the other hand, the influence of repeated baking was shown in the thermal expansions of porcelains. However, that influence becomes remarkable above $650^{\circ} \mathrm{C}$, which is higher than the glass transition temperature of porcelain (i.e., $570^{\circ} \mathrm{C}$ ). Therefore, it is hard to speculate whether the strain is accumulated. Accordingly, the possibility of an adverse influence by repeated baking on mechanical property and color is low.

\section{MOE concern}

It is generally believed that when metals with higher MOE values are used, the resultant porcelain-fired bond strengths are expected to be higher. Furthermore, even if a metal such as DnTi with a larger MOE value than that of the porcelain was used, the bond strength was lower than the bend strength of the single enamel porcelain layer. One might think that such a result is because of a shifting of center of the bending by the bigger elastic modulus of the metal. Then, shifting of the bending center caused high stress on the surface of the porcelain. Hence, results from bend tests were analyzed with the finite element method.
As seen in Fig. 15, the triple-layered porcelain baked onto metals had a lower tensile stress than the case OP57 porcelain. Also, the tensile stress of the porcelain surface barely falls off, as the MOE of metals elevates. These results suggest that bend strengths improve when the MOE of metals becomes bigger, contradicting the experiment result of the flexural strength of Fig. 2. On the other hand, the analysis in the case when the metal was set in the tensile side and the analysis in the case when the porcelain was set in the tensile side agree very well with the experiment result, therefore these results support the validity of the numerical analysis. Thereupon, we did the analysis in case where the test piece was refrigerated. As shown in Fig. 16, at the time of refrigeration, compressive stress occurs in opaque porcelain (A1O) and body porcelain (A1B), but tensile stress occurs in enamel porcelain (OP57). In the case where the bending load was added to this condition, higher tensile stress occurred on the surface of porcelain than the single layer's OP57 porcelain, and porcelain-fired metal reduced the bend strengths. As the cause of the thermal expansion of enamel porcelain was only slightly bigger than that of body porcelain, such a phenomenon is conceivable. It is well known that the thermal expansions of the metal and porcelains have an influence on bond strength. It is therefore designed for compressive stress to happen in porcelain at the time of refrigeration.

\section{Neutral axis position in beams}

Even if opaque, body and enamel porcelains were fired to metals, since their MOE values and coefficients of thermal expansion values are similar, they can be treated as if they are a single layer instead of a triple layer. Hence the porcelains fired to a metal sample can be considered as a double-layer thin plate. When a thin plate of a double layer structure is subjected to the tree pointy bend tests, unlikely in the mono-layer case, if may not be necessary for the central (neutral) axis to be on the geometrical center line of the beam. It is located rather far from the geometrical center line due to a large discrepancy in values of MOE between porcelain and metal. Using an equation ${ }^{19)}$, the location of the central axis line was calculated. For these calculations, MOE for porcelain was $70.984 \mathrm{GPa}$ (averaged over opaque, body and enamel porcelains, as shown in Fig. 4 at the first baking cycle) and MOE values for metals are also used as shown in the zero baking cycle (see Fig. 5). For the sake of simplicity, the thickness of metal was $0.5 \mathrm{~mm}$ and porcelain portion thickness was 1.5 $\mathrm{mm}$. It was found that for OP57 - single porcelain application -, the central line is located exactly at the geometrical center line (which is $1.0 \mathrm{~mm}$ from the bottom). This agrees very well as the result of the FEM calculation, as shown in Fig. 15. For the 
DnTi+P case, the metal-porcelain interface was 0.5 $\mathrm{mm}$ from the bottom, but the central line was calculated to be $0.82 \mathrm{~mm}$ from the bottom, which is inside the porcelain portion. Again the stress distribution curve (Fig. 15) for the DnTi+P case agrees with this calculation very well. For the P+DnTi case, the porcelain-metal interface was $1.5 \mathrm{~mm}$ from the bottom of the specimen. The calculated center line was 1.18 $\mathrm{mm}$ from the bottom, while the calculated center lines for the P+KIK was $1.10 \mathrm{~mm}$ and for the P+J2 was $1.01 \mathrm{~mm}$, respectively. All these lines are very close to the zero stress line according to the FEM analysis with small differences of less than $10 \mathrm{MPa}$.

\section{Stresses at porcelain surface and interface}

When the alloy DnTi was placed at the tensile stress side $(\mathrm{DnTi}+\mathrm{P})$, the maximum tensile stress was located at the metal-porcelain interface at $\mathrm{P} 1$, as marked on Fig. 17, which was about $12 \mathrm{MPa}$. On the other hand, when the porcelain side was placed on the maximum tensile stress side, the maximum stress could be found at P3, which was $58 \mathrm{MPa}$. The difference was about a factor of 5 , which is close enough to the factor of 6 as previously mentioned in Fig. 3.

\section{Porcelain/metal interfacial stresses}

Fig. 17 shows the stress distribution curves for $\mathrm{P}+\mathrm{DnTi}$ and DnTi+P cases. There are several common points between these two cases regardless of the way the sample was placed during the three-point bending tests; (1) stress gradients inside the porcelain (between $0.5 \mathrm{~mm}$ and $1.5 \mathrm{~mm}$ from the bottom) should be same for both cases (in other words, they should be parallel to each other), and (2) stress patterns for DnTi metal (from 0 to $0.5 \mathrm{~mm}$ and 1.5 to $2.0 \mathrm{~mm}$ ) should also be the same. If these stress gradients are extrapolated and intersection points are marked as seen in Fig. 17, there are M1 and M2 at the P/DnTi interface and P1 and P2 at the DnTi/P interface. Since stress differences between these points should be considered as interfacial stress, 19.1 $\mathrm{MPa}$ was found between $\mathrm{M} 1$ and $\mathrm{M} 2$ and $18.5 \mathrm{MPa}$ between $\mathrm{P} 1$ and P2. Hence the interfacial stress that developed in DnTi metal and OP57 porcelain can be approximated to be $20 \mathrm{MPa}$.

The effect of mechanical stressing on the thermal-stressed condition was examined, and the results are shown in Fig. 16. The non-stressing condition was represented by $\mathrm{P}+\mathrm{DnTi}-470^{\circ} \mathrm{C}+0 \mathrm{Kg}$. When this sample was under bending stress, the original stress distribution (shown with dotted line) was redistributed and appeared to be close to the line shown for $\mathrm{P}+\mathrm{DnTi}$, except that a large tensile interfacial stress at the porcelain-metal interface (which is located at $1.5 \mathrm{~mm}$ from the bottom) still remained to some extent in the adverse side. It was also found that the interfacial stress that developed in porcelain and DnTi metal was $45 \mathrm{MPa}$ in tension (between
PM1 and PM2 points in Fig. 16).

\section{CONCLUSIONS}

A single application of opaque, body and enamel porcelains from the Vintage halo porcelain systems and a triple application of these porcelains on three metals plates were repeated up to 10 times, and the effects of baking cycles on mechanical properties, color characteristics, and thermal properties were investigated. Based on obtained information on thermal and mechanical properties, FEM stress analysis was conducted to further investigate the internal stress distribution as well as interfacial stress build-up between porcelain and metal layers.

Within limited results, it was concluded that, by increasing baking cycles, (1) the bend strengths increased, (2) changes in color characteristics were very small in the Vintage halo porcelain system, and (3) the maximum interfacial stress (about $20 \mathrm{MPa}$ ) was found at the porcelain/metal interface.

\section{REFERENCES}

1) Watanabe K, Ohnishi E, Kaneshima T, Mine A, Yatani $\mathrm{H}$. Porcelain veneer bonding to enamel with plasma-arc light resin curing, Dent Mater J 2002; 21: 61-68.

2) Arikawa H, Kanie T, Fujii K. Mechanical properties of light-cured composite resins cured through filters that simulate enamel, Dent Mater J 2002; 21: 147-155.

3) Suese K, Kawazoe T. Wear resistance of hybrid composite resin for crown material by the two-body sliding test, Dent Mater J 2002; 21: 225-237.

4) Yoshida Y, Shirai K, Shintani H, Okazaki M, Suzuki K, Meerbeek VB. Effect of presilanization filler decontamination on aesthetics and degradation resistance of resin composites, Dent Mater J 2002; 21: 383-395.

5) Arikawa H, Kanie T, Fujii K, Homma T, Takahashi H, Ban S. Optical properties of paint-on resins for shade modification of crown and bridge resins - Light transmittance characteristics-, Dent Mater J 2002; 22: 272-279.

6) Okamoto M, Mine A, Watanabe K, Kawahara D, Yatani H. Porcelain veneer bonding to dentin and the curing performance of plasma-arc light with respect to porcelain thickness, Dent Mater J 2002; 21: 313-320.

7) Japan Education Committee for Dental Technicians. Textbook for dental technicians - dental materials science. Vol.1. Tokyo: Ishiyaku Pub.; 1999, p.80.

8) Society of dental materials. Dental materials science. Tokyo: Ishiyaku Pub; 1982, p.191.

9) Phillips RW. Skinner's Science of dental materials. $8^{\text {th }}$ ed. Philadelphia: W. B. Saunders; 1982, P.515.

10) Barghi N, Goldberg J. Porcelain shade stability after repeated firing, J Prosthet Dent 1977; 37: 173-175.

11) Ohtake A. Studies on physical properties of porcelain fused to metal and its clinical techniques - for opaque porcelain-, SHIGAKU 1971; 59(5): 324-343.

12) Iwata T. Studies on physical properties of porcelain 
fused to metal - the effect of fusing temperature-. SHIGAKU 1980; 68: 261-282.

13) Kuroe R. Studies on physical properties of porcelain fused to metal - for enamel porcelain - . J J Prosthodontic Soc 1975; 19: 97-108.

14) Yamada S, Sato T, Sakaguchi K, et al. Effect of condensation of porcelains on strength and internal structure I. On firing temperature. J J Prosthodontic Soc 1970; 14: 22-32.

15) Kasai, A.: Experimental studies on the changes of form of dental porcelains during firing, $\mathrm{J} J$ Prosthodontic Soc 1971; 15: 149-177.

16) Nagasawa S, Yoshida T, Mizoguchi H, et al. Porcelain- metal bonding: Effects of repeated baking process, BioMedical Materials and Engineering 2001; 11: 185-195.

17) American society for metals. Metal handbook Vol.1. $8^{\text {th }}$ ed. Metals Park: American society for metals; 1973, p.1201.

18) American society for metals. Metal handbook Vol.8. $8^{\text {th }}$ ed. Metals Park: American society for metals; 1973, p.287.

19) Oshida Y, Reyes MJD. Titanium-porcelain system. part IV: Some mechanistic considerations on porcelain bond strengths, Bio-Medical Materials and Engineering 2001; 11: 137-142. 